\title{
Implementasi Bauran Komunikasi Pemasaran RS Hermina Karawang di Era Pandemi Covid19
}

\section{Implementation of Marketing Communication Mixes Hermina Karawang Hospital in The Era of Pandemic Covid19}

\author{
Shita Hayyuning Astiti ${ }^{1}$, Yaslis Ilyas ${ }^{2}$ \\ ${ }^{1}$ Kajian Administrasi Rumah Sakit, FKM, Universitas Indonesia \\ ${ }^{2}$ Fakultas Kesehatan Masyarakat, Universitas Indonesia \\ email: shitaastiti@gmail.com; Depok, Jawa Barat
}

\begin{abstract}
ABSTRAK
Bauran komunikasi pemasaran rumah sakit menjadi satu hal yang vital pada rumah sakit di Indonesia terutama di era pandemi Covid19 yang terjadi sejak awal tahun 2020. RS Hermina Karawang merupakan salah satu dari empat rumah sakit yang ditunjuk Pemerintah Kabupaten Karawang untuk menjadi rumah sakit rujukan Covid19 di Kabupaten Karawang, Jawa Barat. Tujuan penelitian ini untuk mengetahui implementasi elemen bauran promosi/komunikasi pemasaran yang digunakan oleh RS Hermina Karawang di era Covid19 sepanjang tahun 2020. Penelitian ini menggunakan desain deskriptif melalui metode observasi dan wawancara terstruktur. Didapatkan hasil penelitian bahwa RS Hermina Karawang telah menerapkan seluruh bauran komunikasi promosi pemasaran walaupun ada beberapa yang belum efektif, yaitu periklanan, promosi penjualan, hubungan masyarakat dan publisitas, pemasaran langsung, pemasaran interaktif, pemasaran dari mulut ke mulut dan penjualan personal. Selama pandemi berlangsung hubungan masyarakat belum maksimal dilakukan sehingga evaluasi secara spesifik perlu dilakukan untuk mencegah masalah atau kendala terjadi berulang.
\end{abstract}

Kata kunci : Bauran Promosi, Komunikasi Pemasaran Rumah Sakit, Pandemi Covid19

\begin{abstract}
The hospital communication marketing mix has become vital for hospitals in Indonesia, especially in the era of the Covid-19 pandemic that has occurred since the beginning of 2020. Hermina Karawang Hospital is one of the four hospitals appointed by the Karawang Regency government to be a Covid-19 referral hospital in Karawang, West Java. This research aimed to determine the implementation of the promotion/communication marketing mix elements used by Hermina Karawang Hospital in the Covid-19 era throughout 2020. This research design is descriptive through the method of observation and structured interviews. The results show that Hermina Karawang Hospital had implemented the entire promotion communication marketing mix, although some were not effective, namely advertising, sales promotion, public relations and publicity, direct marketing, interactive marketing, word of mouth marketing personal selling. During the pandemic, public relations have not been maximally fulfilled; thus, specific evaluations need to be carried out to prevent recurring problems/constraints.
\end{abstract}

Keywords: Promotion mix, Hospital Marketing Communication, Covid Pandemic19 
Shita Hayyuning Astiti, Yaslis Ilyas : Implementasi Bauran Komunikasi Pemasaran ....

\section{PENDAHULUAN}

Manajemen komunikasi pemasaran rumah sakit merupakan salah satu bagian yang penting dalam rangka menjalankan kegiatan promosi rumah sakit. Kegiatan promosi secara efektif banyak ditentukan oleh penentuan strategi komunikasi. Didapatkan pula, "Marketing communications are means by which firms attempt to inform, persuade, and remind comsumers - directly or indirectly - about the products and brands they sell" (Kotler, 2012), atau bisa diartikan bahwa komunikasi marketing adalah hal yang dilakukan perusahaan untuk memberikan informasi, membujuk serta mengingatkan konsumen, baik secara langsung maupun tidak langsung, mengenai produk barang atau jasa yang perusahaan jual.

Rumah sakit merupakan institusi pelayanan kesehatan yang menyelenggarakan pelayanan kesehatan individu secara menyeluruh serta menyediakan pelayanan untuk perawatan inap, perawatan jalan serta keadaan gawat darurat. Berdasarkan pengelolaannya rumah sakit juga dapat berbentuk privat, yaitu dikelola oleh badan hukum dengan tujuan profit (Undang-Undang no.44, 2009). Rumah sakit yang bertujuan profit memiliki usaha-usaha untuk meraih profit, sehingga hal tersebut perlu diatur dalam manajemen pemasaran rumah sakit, khususnya manajemen promosi rumah sakit. Ditambah pula dengan pergeseran mengutamakan pasien atau "patient centered" yaitu pasien mengharapkan pelayanan bermutu dengan harga terjangkau (Heningnurani, 2019).

Rumah sakit dapat menggunakan berbagai bentuk komunikasi pemasaran untuk mempromosikan apa yang mereka tawarkan dan mencapai tujuan finansial. Kegiatan pemasaran yang melibatkan aktivitas komunikasi antara lain periklanan, tenaga penjualan, papan nama toko, display ditempat pembelian, kemasan produk, direct-mail, sampel produk gratis, kupon, publisitas, dan alat-alat komunikasi lainnya, atau dapat disebut sebagai komponen promosi dalam bauran pemasaran (marketing mix) (Shimp, 2018). Komunikasi pemasaran terintegrasi / Integrated Marketing Communication (IMC) merupakan usaha yang dilakukan untuk mengkoordinasikan dan mengendalikan berbagai elemen bauran promosi (periklanan, pemasaran langsung, promosi penjualan, pejualan tatap muka, hubungan masyarakat dan publisitas, pemasaran interaktif) untuk menghasilkan informasi yang fokus pada pelanggan/konsumen yang terpadu dan mampu mewujudkan berbagai tujuan organisasi (Tjiptono, 2016). Sebelum melakukan komunikasi pemasaran terpadu, pemasar perlu mengkombinasikan terlebih dahulu bauran pemasaran yakni produk, harga, distribusi, dan promosi. Bagaimanapun juga, bauran pemasaran harus berpadu secara sinergis dengan ketiga elemen lainnya agar kesuksesan 
dalam promosi dapat tercapai (Kotler, 2002).

Rumah sakit Hermina Karawang berdiri sejak bulan Maret 2020, dan langsung menjadi rumah sakit rujukan Covid19 di daerah tersebut. Hal itu menjadi sebuah tantangan bagi rumah sakit untuk menjamin keselamatan pasien, terutama bagi pasien non-Covid19. Berbagai strategi pemasaran dilakukan, terutama melakukan komunikasi pemasaran untuk menyampaikan informasi mengenai produk layanan rumah sakit serta meyakinkan masyarakat mengenai mutu pelayanan rumah sakit. Strategi yang dijalankan oleh RS Hermina Karawang salah satunya adalah dengan menjalankan kegiatan komunikasi pemasaran terintegrasi. Komunikasi pemasaran ini dilakukan sebagai upaya rumah sakit dalam memberikan informasi, pengetahuan serta mengingatkan pasien mengenai produk layanan rumah sakit. Sebagai rumah sakit tipe $\mathrm{C}$ yang baru berdiri, dibutuhkan kegiatan komunikasi pemasaran yang baik dan efektif sehingga masyarakat mengetahui dan menggunakan produk serta jasa layanan rumah sakit.

\section{METODE}

Penelitian ini menggunakan desain deskriptif. Penelitian ini bertujuan untuk mengetahui implementasi bauran komunikasi pemasaran yang dilakukan oleh RS Hermina Karawang di era Covid19 sepanjang tahun 2020 hingga Januari 2021. Penelitian dilakukan dengan telusur dokumen, wawancara terstruktur dan observasi. Informan ditentukan dengan metode purposive sampling. Narasumber yang ditujukan dalam penelitian ini adalah 1 orang dengan jabatan Direktur RS dan 1 orang dengan jabatan Manajer Pemasaran. Wawancara dilakukan melalui telepon dan videocall, sedangkan data sekunder didapat oleh peneliti langsung dari jurnal ilmiah, buku pustaka dan data rekam medis rumah sakit. Wawancara dilakukan selama observasi kepada para narasumber untuk mendapatkan informasi serta tanya jawab mengenai suatu topik (Sugiyono, 2017), dalam hal ini mengenai implementasi bauran komunikasi pemasaran yang telah dilakukan oleh RS Hermina Karawang di Era Pandemi Covid19 sepanjang tahun 2020 hingga Januari 2021. Wawancara yang digunakan peneliti adalah wawancara tertutup atau terstruktur, karena peneliti menggunakan pedoman wawancara dan berfokus hanya pada topik penelitian (Jaelani, 2013). Observasi dilakukan oleh peneliti sendiri untuk mengamati proses (Sugiyono, 2016) implementasi bauran komunikasi pemasaran yang diterapkan oleh rumah sakit dan mencocokannya dengan hasil wawancara dengan para narasumber. 
Shita Hayyuning Astiti, Yaslis Ilyas : Implementasi Bauran Komunikasi Pemasaran ....

\section{HASIL}

Rumah sakit Hermina Karawang yang berdiri sejak minggu ketiga bulan Maret 2020 dan mengantongi izin operasional pada 3 April 2020, telah menjadi salah satu rumah sakit rujukan Covid19 pada tanggal 20 Maret 2020 sesuai pernyataan juru bicara Satuan Tugas Penanganan Covid19, Achmad Yurianto. Hal ini merupakan sesuatu yang baru bagi Hermina Hospital Group, terutama dalam hal promosi komunikasi pemasaran rumah sakit. Sebagai rumah sakit yang baru sekaligus pusat rujukan Covid19, RS Hermina Karawang perlu untuk memilih bauran promosi yang digunakan dengan tujuannya adalah tersampaikannya informasi yang meyakinkan masyarakat luas mengenai keamanan berobat di rumah sakit sehingga pasien non-covid mendapat kenyamanan untuk datang dan memperoleh pelayanan kesehatan di RS Hermina Karawang.

Dalam menentukan rencana kegiatan promosi/komunikasi pemasaran rumah sakit sebelumnya melakukan analisis SWOT terlebih dahulu yang kemudian menetapkan segmenting, targeting dan positioning. Target pasar sudah ditentukan oleh pusat korporasi, namun pihak cabang perlu mempertajam strategi pemasaran yang akan digunakan. Analisis sebenarnya dilakukan oleh pihak RS Hermina Karawang namun tidak secara detail dan tertulis. Hal tersebut dilakukan oleh tim MADU (Marketing Terpadu) yang disetujui oleh Direktur RS. Tim MADU terdiri dari Manajer Marketing, Manajer bidang bagian lain, Kepala Instalasi dan Kepala Ruang Perawatan. Penetapan rencana kegiatan promosi rumah sakit ditentukan berdasarkan target yang telah ditentukan oleh korporat melalui penetapan FS (Feasibility Study). Manajer marketing berfungsi membantu direktur dalam menjalankan program marketing yang nantinya mengawasi jalannya program tersebut yang dijalankan oleh staf marketing, yang dibantu oleh Manajer bidang bagian lain, serta Kepala Instalasi dan Kepala Ruang Perawatan.

Direktur RS Hermina Karawang memandang promosi rumah sakit di era pandemi Covid19 adalah suatu hal yang menantang dan perlu untuk ditata dengan apik untuk menghasilkan output yang sesuai, serta yang utama dari tujuan promosi RS Hermina Karawang adalah dapat meyakinkan masyarakat mengenai keamanan berobat di RS Hermina Karawang bagi pasien non-covid19. Berdasarkan hasil wawancara, RS Hermina Karawang telah melaksanakan bauran promosi secara keseluruhan.

Pada dasarnya komunikasi pemasaran terintegrasi merupakan sarana yang digunakan perusahaan (dalam hal ini rumah sakit) untuk memberikan informasi kepada konsumen melalui beberapa cara yang diharapkan mempengaruhi pengambilan keputusan konsumen. Seperti penelitian yang dilakukan terdahulu berjudul Strategi Komunikasi 
Pemasaran Terpadu (Rahardi, 2017), kegiatan IMC (Integrated Marketing Communication) telah dilakukan oleh perusahaan namun tetap didapatkan adanya kendala dalam pelaksanaan lapangan. Pemanfaatan elemen promosi dalam komunikasi pemasaran terintegrasi yang diterapkan oleh RS Hermina Karawang:

\section{Periklanan (advertising)}

RS Hermina Karawang memanfaatkan media cetak dan digital dalam mengiklankan produk dan jasa layanan kesehatan yang disediakan. Media cetak yang digunakan adalah poster yang dipasang di tiap sudut dalam rumah sakit (baik itu poster yang memberikan informasi seputar penyakit maupun tentang jasa layanan kesehatan rumah sakit), banner yang dipasang mulai dari pintu gerbang rumah sakit hingga di dalam area rumah sakit, dan leaflet. Sedangkan untuk media digital yang digunakan adalah website, Facebook, Instagram, SMS radius dan aplikasi Halo Hermina.

\section{Promosi penjualan (sales promotion)}

Untuk menarik konsumen agar mau menggunakan layanan kesehatannya RS Hermina Karawang memberikan beberapa pilihan paket untuk pasien non-covid seperti paket persalinan normal maupun SC (section caesarea), MCU (Medical Check Up) dan paket skrining Covid19. Hal ini dipilih karena sesuai dengan visi RS Hermina Karawang yang memiliki layanan unggulan ibu dan anak, dan sesuai dengan posisi rumah sakit yang berada di kawasan industri dengan banyak pabrik sehingga demand MCU (Medical Check $U p$ ) menjadi salah satu layanan yang diminati. Sama halnya dengan paket skrining Covid19 yang banyak diminati oleh beberapa perusahaan wilayah sekitar yang menjadi salah satu langkah preventif perusahaan dalam penanganan Covid19.

\section{Penjualan personal (personal selling)}

Penjualan personal termasuk salah satu elemen promosi yang sering dilakukan oleh tim marketing rumah sakit dalam meyakinkan individu untuk datang dan menggunakan produk serta jasa layanan rumah sakit. Contohnya adalah PMO (Personal Maternity Officer) yang bertugas memberikan informasi kepada pasien kebidanan mengenai produk dan jasa layanan kesehatan seputar kebidanan yang tersedia di RS Hermina Karawang. Penerapan lainnya adalah dengan mendatangi langsung perusahaan yang membutuhkan layanan kesehatan MCU. Menurut manajer marketing RS Hermina Karawang, seluruh karyawan rumah sakit telah menerapkan personal selling secara tidak langsung, yakni dengan memberikan informasi mengenai rumah sakit kepada calon konsumen apabila ada kolega yang menanyakan segala sesuatu tentang RS Hermina Karawang ataupun kepada konsumen yang telah berada di rumah sakit. 
Shita Hayyuning Astiti, Yaslis Ilyas : Implementasi Bauran Komunikasi Pemasaran ....

\section{Hubungan masyarakat (public relation)}

Manajer marketing RS Hermina Karawang menuturkan bahwa hubungan masyarakat memang telah dilakukan oleh pihak marketing namun memang belum sepenuhnya dikarenakan keadaan pandemi Covid19. Biasanya rumah sakit mengadakan gathering ataupun mengikuti acara kemasyarakatan untuk membina hubungan dengan masyarakat, namun karena pandemic hal tersebut tidak dapat berjalan. Sejauh ini, hubungan masyarakat yang dilakukan adalah dengan menggunakan media sosial yang disiarkan secara langsung, yaitu IG (Instagram) Live.

\section{Pemasaran langsung (direct marketing)}

Pemanfaatan pemasaran langsung dilakukan oleh staf marketing dengan cara mengirim email ataupun telepon perusahaan-perusahaan di wilayah Karawang serta melakukan follow-up, hal itu dilakukan supaya terjadi peluang interaksi yang lebih besar. Dengan kondisi pandemi Covid19, komunikasi pemasaran rumah sakit berjalan baik dengan menggunakan telepon dan email.

\section{Pemasaran interaktif (interactive marketing)}

Menurut penelitian penulis, rumah sakit memiliki website serta sosial media yang berisi banyak informasi mengenai layanan kesehatan rumah sakit. Rumah sakit mengadakan acara "Meet the Doctor" pada Instagram yang disiarkan secara live. Para pengguna internet dapat menyaksikan dan menulis pertanyaan yang akan dijawab oleh pihak rumah sakit. Selain itu rumah sakit juga menyediakan aplikasi telemedicine yang bernama "Halo Hermina" sehingga pasien dapat berinteraksi dengan dokter dan mendapat jawaban secara langsung melalui video daring. Telemedicine merupakan hal baru namun mulai disambut baik oleh konsumen.

\section{Mulut ke mulut (word of mouth)}

Rumah sakit belum memiliki data yang spesifik mengenai hal ini dikarenakan belum dilakukannya monitoring dan evaluasi. Namun perencanaan pelaksanaan telah dilakukan untuk monitoring dan evaluasi menggunakan tools survey motivasi pasien baru.

Menurut hasil penelitian penulis, monitoring dan evaluasi promosi rumah sakit belum dilakukan secara spesifik, namun untuk keseluruhan rumah sakit mencoba mengevaluasi melalui kinerja rumah sakit berdasarkan pendapatan (keuangan), angka kunjungan rawat jalan, angka rawat inap, angka operasi dan angka kelahiran. 


\section{PEMBAHASAN}

Pada era pandemi Covid19 setiap rumah sakit pemerintah maupun swasta perlu untuk lebih memperhatikan mengenai kualitas pelayanannya agar rumah sakit yang bersangkutan dapat benar-benar menjaga kualitas pelayanannya karena itu merupakan hal penting apabila rumah sakit ingin benar-benar bekerja secara efisien dan efektif serta menjaga kelangsungan hidupnya. Perhatian perlu lebih diberikan kepada pasien, dan hal tersebut diwujudkan dengan mempehatikan kebutuhan dan keinginan mereka (Rahmawati, 2018).

Bauran komunikasi marketing terdiri atas advertising, sales promotion, public relation, personal selling, interactive marketing, direct marketing dan word of mouth (Kotler, 2012). Kegiatan tersebut menunjang terjadinya komunikasi, seperti yang dijabarkan dalam penelitian ini. Awal mula RS Hermina Karawang berdiri memberikan totalitas pelayanan untuk pasien Covid19 khusus rawat inap dengan menerima rujukan dari rumah sakit lain. Namun sejak bulan Mei 2020 mulai dibuka pelayanan poli rawat jalan untuk pasien non-Covid19. Dengan menjalankan bauran promosi/promosi pemasaran yang telah disebutkan, berdasar data rekam medis tercatat rumah sakit Hermina Karawang sepanjang tahun 2020 telah melayani total sebanyak 2222 pasien rawat jalan dan 220 pasien rawat inap baik dengan Covid19 maupun tidak.

Tren menurut data rekam medis RS Hermina Karawang tahun 2020, total pasien baru poli rawat jalan cenderung naik. Terdapat kenaikan total pasien baru poli rawat jalan pada TW ke3 (Juli, Agustus, September) sebesar 326,5\% dibandingkan TW ke2 (April, Mei, Juni) dan terjadi kenaikan total pasien baru pada TW ke4 (Oktober, November, Desember) sebesar 12,9\% dibandingkan TW ke3. Untuk total pasien lama juga mengalami kenaikan pada TW ke3 sebesar 259,3\% dan pada TW ke4 sebesar 160,4\%. Untuk total pasien baru IGD pada TW ke3 (Juli, Agustus, September) sebesar 696\% dibandingkan TW ke2 (April, Mei, Juni), namun terjadi penurunan sebesar 10\% pada TW ke4 (Oktober, November, Desember). Jumlah total pasien lama dan baru tersebut tidak lepas dari peran tim marketing rumah sakit.

Media iklan yang digunakan RS Hermina Karawang adalah media cetak dan digital. Instagram merupakan salah satu media promosi digital yang digunakan. Berdasarkan hasil observasi peneliti, konten Instagram banyak memberikan informasi mengenai jenis pelayanan rumah sakit, penjelasan mengenai penyakit secara umum khususnya yang terbaru mengenai pandemi Covid19, jadwal praktek dokter, jadwal webinar, serta promosi mengenai fasilitas terbaru rumah sakit yaitu konsultasi online 
Shita Hayyuning Astiti, Yaslis Ilyas : Implementasi Bauran Komunikasi Pemasaran ....

dengan dokter melalui "Halo Hermina". Hal ini senada dengan penelitian sebelumnya bahwa menggunakan media promosi seperti leaflet, website sebagai bentuk promosi program dapat meningkatkan angka kepatuhan minum obat pasien (Masyfufah, 2016).

Dari data yang didapat, jumlah pengikut RS Hermina Karawang mengalami peningkatan sejak awal pemantauan yakni sejak bulan Agustus 2020 hingga Januari 2021 mengalami peningkatan sebanyak $35 \%$, dengan penambahan pengikut terbesar terjadi pada bulan Januari 2021 sebanyak 137 pengikut baru. Selain instagram, menurut hasil observasi peneliti pihak rumah sakit juga menggunakan website sebagai media promosi digital yang memberikan informasi rumah sakit yaitu alamat, nomor kontak, jenis pelayanan serta jadwal dokter praktek sekaligus membuat janji temu sehingga pasien tidak perlu datang langsung ke rumah sakit untuk mendaftar, terutama dalam kondisi pandemi Covid19 saat ini. Hal ini senada dengan penelitian di RS Islam Surabaya (Rachmi, 2020) bahwa isi pesan periklanan dalam media cetak dan digital untuk memberikan informasi secara garis besar mengenai pelayanan rumah sakit untuk mengikuti teknologi saat ini dimana lebih mudah untuk mengakses online.

Penerapan promosi RS Hermina Karawang yang dilakukan oleh tim MADU adalah dengan penawaran paket persalinan normal, MCU (Medical Check Up) dan screening Covid19 dengan mengedepankan informasi mengenai keamanan berobat di RS Hermina Karawang. Pemilihan paket MCU di RS Hermina Karawang yang ditawarkan oleh tim MADU merupakan paket pemeriksaan kesehatan menyeluruh yang ditawarkan baik kepada karyawan perusahaan maupun masyarakat umum yang baru dilontarkan pada bulan Agustus 2020. Jumlah konsumen sempat melonjak pada bulan September 2020 sebanyak 257 pemeriksaan dikarenakan adanya tender dan menggunakan potongan harga, namun kemudian berkurang dan mulai naik perlahan hingga bulan Januari 2021 menjadi 44 pemeriksaan. Hal ini senada dengan penelitian berjudul "Strategi Komunikasi Pemasaran Rumah Sakit Mata Pekanbaru Eye Center (PBEC) Dalam Membangun Brand Awareness" (Wahyuni, 2019) hasil dari pengamatan adalah rumah sakit Mata PBEC menggunakan potongan harga atau diskon untuk menawarkan dan mengenalkan produk baru rumah sakit.

Personal selling adalah komunikasi tatap muka antara penjual dan calon konsumen untuk membentuk pemahaman mengenai produk dan jasa yang diharapkan akan dibeli oleh calon konsumen (Tjiptono, 2008). Dalam penerapan personal selling RS Hermina Karawang mengandalkan PMO (Personal Maternity Officer) untuk memberikan informasi seputar produk dan jasa layanan rumah sakit di bidang kebidanan sehingga 
dapat meyakinkan pasien untuk menggunakan produk dan jasa layanan rumah sakit. Hal ini senada dengan peneliltian di RS Mata Pekanbaru Eye Center (PBEC) (Wahyuni, 2019), personal selling dilakukan dengan melakukan kegiatan sosialisasi sehingga RS Mata PBEC dapat menjelaskan keunggulan rumah sakit dan meyakinkan masyarakat untuk berobat di rumah sakit tersebut.

Menurut penelitian yang sama (Wahyuni, 2019), pemasaran langsung lebih mudah ditelusuri terutama konsumen yang memberikan respon. Salah satu yang digunakan oleh rumah sakit dengan menggunakan telepon. Melalui telepon, informasi yang ingin disampaikan oleh rumah sakit dapat tersampaikan langsung dan memang merupakan kebutuhan konsumen. Selain telepon, rumah sakit juga menggunakan surat sebagai perantara pelaksanaan kegiatan sosialisasi sehingga informasi yang dibutuhkan oleh konsumen dapat tersampaikan secara detail melalui surat. Hal ini sesuai dengan kegiatan direct marketing yang dilakukan oleh RS Hermina Karawang yang menggunakan telepon, aplikasi whatsapp dan email untuk mendapat respon dari konsumen yang membutuhkan layanan kesehatan RS Hermina Karawang. Tren pendaftaran pasien poli rawat jalan melalui aplikasi whatsapp mengalami peningkatan sejak pemantauan pada bulan November 2020, yaitu naik 6,8\% pada bulan Desember 2020 dan naik 47,2\% pada bulan Januari 2021.

Menurut hasil wawancara dengan informan kegiatan hubungan masyarakat di masa pandemi Covid19 kurang maksimal untuk dilakukan. Namun rumah sakit Hermina Karawang berusaha menjaga hubungan baik dengan konsumen dan juga rekan-rekan bisnis seperti puskesmas di Kabupaten Karawang, perusahaan-perusahaan di Kabupaten Karawang maupun rumah sakit lain di wilayah yang sama. Usaha tersebut sama dengan rumah sakit Islam Malahayati yaitu humas dilakukan untuk menjaga image rumah sakit yaitu dengan menjalin hubungan baik dengan instansi-instansi di kota Medan (Herfiza, 2018). Senada dengan penelitian sebelumnya pula yang mengatakan bahwa citra suatu rumah sakit agar dikenal masyarakat butuh waktu yang tidak sebentar dan butuh rencana matang (Hermawati et al., 2014). Hal tersebut berbeda dengan kondisi sebelum pandemi seperti hasil dari penelitian sebelumnya bahwa komunikasi pemasaran dalam hubungan masyarakat dilakukan dengan melakukan kegiatan khitanan massal, pengobatan gratis dan ikut serta dalam car free day menggunakan kostum medis (Lestari, 2015). Namun begitu, RS Hermina Karawang tetap memaksimalkan kegiatan hubungan dengan masyarakat secara online yaitu dengan menjalankan live Instagram pada masa pandemi Covid19. 
Shita Hayyuning Astiti, Yaslis Ilyas : Implementasi Bauran Komunikasi Pemasaran ....

Penerapan elemen marketing interactive memiliki kendala utama (Kotler, 2012) yaitu merancang tampilan yang atraktif pada kunjungan pertama dan cukup menarik pengunjung untuk menggunakan kembali. Berdasar penelitian, RS Hermina Karawang selama masa pandemi Covid19 menggunakan media live Instagram untuk menarik interaksi masyarakat serta penggunaan telemedicine yang sedang disempurnakan sejak awal penggunaannya pada bulan Agustus 2020.

Berdasar data yang peneliti dapatkan, hingga bulan Januari 2021 tim MADU telah melakukan kegiatan live Instagram sebanyak 14 kali dengan tema berbeda seputar kesehatan, dan memiliki total viewer rata-rata sebanyak 457 orang dengan viewer terbanyak pada tema "Bersama melawan Covid19". Hasil ini senada dengan pengamatan penelitian yang dilakukan oleh Wahyuni (2019) mengenai kegiatan pemasaran interaktif, hasil penelitian menunjukkan bahwa RS Mata PBEC menggunakan alat pemasaran interaktif dengan adanya website dan media sosial. Dalam hal ini sosial media yang digunakan RS Mata PBEC adalah facebook dan instagram. Dalam penelitian lainnya juga disebutkan bahwa rumah sakit membuat website sehingga bisa diakses oleh masyarakat (Lestari, 2015).

Direct marketing dapat diartikan sebagai suatu sistem dalam pemasaran yang menggunakan satu atau beberapa media iklan sehingga menimbulkan respon yang dapat diukur (Tjiptono, 2016). Pada penelitian sebelumnya, di RS mata Pekanbaru Eye Centre (PBEC) (Wahyuni, 2019) melakukan pemasaran langsung, penjualan personal dan hubungan masyarakat dengan menggunakan internet untuk hasil yang lebih efisien dan efektif. Penggunaan internet era ini sudah sangat luas sehingga mempermudah tim marketing rumah sakit untuk melakukan tugas dan fungsinya. Hal ini sesuai dengan hasil wawancara yang didapatkan peneliti bahwa RS Hermina Karawang melakukan direct marketing melalui telepon dan email. Menurut peneliti hal ini sesuai dengan kondisi pandemi Covid19 yang mengharuskan untuk mengurangi kontak langsung dan melalui telepon serta email respon yang didapat adalah respon langsung dari konsumen. Staf pemasaran rumah sakit juga melakukan pendekatan melalui telepon untuk memberikan penawaran paket MCU (Medical Check Up) kepada perusahan-perusahaan sekitar rumah sakit.

Walaupun evaluasi terhadap elemen word of mouth belum dilakukan, namun pihak RS Hermina Karawang sependapat dengan hasil penelitian di RS PBEC (Wahyuni, 2019) dengan memberikan pelayanan sebaik-baiknya itu merupakan bagian dari komunikasi pemasaran dengan teknik word of mouth. Apabila pasien merasa puas maka 
dengan sukarela pasien akan menyebarkan informasi kepada orang-orang di sekitarnya mengenai kepuasan pelayanan yang didapatkan di rumah sakit. Jadi, apabila pasien baik covid maupun non-covid19 mendapatkan pelayanan terbaik dan aman tentunya akan memberikan efek loyalty pada pasien tersebut dan secara tidak langsung pasien akan menyebarkan informasi mengenai pelayanan yang didapatkannya kepada orang lain. Seperti yang diungkap dalam penelitian bahwa pasien RSI Jemursari Surabaya telah puas dengan pelayanan poli umum karena karyawan bersikap baik, serta ramah (Wijaya \& Adriansyah, 2020).

Media promosi memegang peranan penting dalam membentuk citra rumah sakit, maka dari itu perlu direncanakan secara matang oleh rumah sakit. Seperti tertuang dalam penelitian sebelumnya, citra rumah sakit XYZ masih belum optimal sehinggga komponen promosi perlu dibuat lebih menarik dengan memikirkan akses masyarakat luas yang terbatas (Maulana, 2020). Adapun kendala yang dihadapi dalam menjalankan kegiatan promosi dapat dijadikan sebagai acuan dalam perencanaan pengembangan perusahaan (Listyawati \& Akbar, 2016).

\section{SIMPULAN}

Elemen komunikasi pemasaran yang digunakan RS Hermina Karawang antara lain periklanan, personal selling, pemasaran interaktif. Selain itu telah melaksanakan hubungan masyarakat namun tidak bisa dilakukan secara maksimal, upaya yang dicoba adalah melalui versi digital dengan menggunakan aplikasi live Instagram. Untuk kegiatan pemasaran langsung dilakukan melalui telepon dan email ke perusahaan yang membutuhkan jasa pelayanan RS Hermina Karawang. Berdasarkan data terdapat peningkatan jumlah total pasien lama dan baru, baik rawat inap maupun rawat jalan. Pada media digital tercatat pula peningkatan salah satunya adalah pengikut Instagram sejak bulan Agustus 2020 hingga Januari 2021, penonton live Instagram dan terdapat peningkatan pada sistem registrasi pasien poliklinik dari yang pada awalnya datang langsung menjadi pendaftaran baik via whatsapp maupun website.

\section{UCAPAN TERIMA KASIH}

Kepada Rumah Sakit Hermina Karawang yang telah bersedia menjadi lokasi serta obyek penelitian saya. Kepada Fakultas Kesehatan Masyarakat Program Studi Magister Kajian Administrasi Rumah Sakit Universitas Indonesia sebagai tempat saya menimba ilmu serta pembimbing akademis saya untuk dukungannya. Kepada Stikes 
Shita Hayyuning Astiti, Yaslis Ilyas : Implementasi Bauran Komunikasi Pemasaran ....

Yayasan Dr. Soetomo Surabaya yang memfasilitasi dan bersedia menerbitkan penelitian ini.

\section{DAFTAR PUSTAKA}

A, Shimp, Terence. (2018). Advertising, Promotion, and Other Aspects of Integrated Marketing Communications, Boston: Cengage.

Herfiza, A. (2018). Komunikasi Pemasaran Rumah Sakit Islam Malahayati dalam Meningkatkan Kunjungan Pasien di Kota Medan. Jom Fisip, 5(1), 1-11.

Hermawati, T., Utari, P., \& Arifin, H. (2014). Strategi Komunikasi Pemasaran Rumah Sakit Sebagai Upaya Peningkatan Publisitas. Jurnal Komunikasi Massa, 7(2), 112-120.

Heningnurani, A. Y. (2019). Strategi Pemasaran RSUD H Abdul Manap Kota

Jambi. Jurnal Administrasi Rumah Sakit Indonesia, 5(3), 153-164. http://journal.fkm.ui.ac.id/arsi/article/view/2897

Kafa, R. (2013). Pengaruh Bauran Pemasaran Jasa Terhadap Keputusan Pasien Dalam Memilih Jasa Rumah Sakit. Ekibisi, 8(1), 105-122.

Kotler, dan Keller. (2012). Manajemen Pemasaran. Edisi 12. Jakarta : Erlangga

Lestari, S. P. (2015). Hubungan Komunikasi Pemasaran Dan Promosi Dengan

Keputusan Memilih Jasa Layanan Kesehatan (Studi Pada Rumah Sakit Islam Lumajang). Interaksi: Jurnal Ilmu Komunikasi, 4(2), 139-147. https://doi.org/10.14710/interaksi,4,2,139-147

Lestari, P., \& Rindu, R. (2018). Hubungan Pemasaran Rumah Sakit (Marketing Mix 7P) terhadap Tingkat Kunjungan Pasien. Jurnal Ilmu Kesehatan Masyarakat, 7(02), 120-130. https://doi.org/10.33221/jikm.v7i02.114

Listyawati, A. A., \& Akbar, M. (2016). Strategi Komunikasi Pemasaran Terintegrasi Dalam Meningkatkan Jumlah PengunjungTaman Nasional Kutai $\begin{array}{llll}\text { Kalimantan Timur. Komunikas KAREBA, } & \text { 5(1), }\end{array}$ http://garuda.ristekbrin.go.id/documents/detail/622367

Lumbantoruan, B. M. (2019). Strategi Komunikasi Dalam Promosi RSUD Doloksanggul Tahun 2018. In thesis (Vol. 2009, Issue 75).

Masyfufah, L. (2016). Upaya Social Marketing Guna Meningkatkan Adherence Minum Obat Pasien Upipi Rsud Dr. Soetomo Surabaya. Jurnal Manajemen $\begin{array}{lllll}\text { Kesehatan Yayasan RS.Dr. Soetomo, } & \text { 2(1), }\end{array}$ https://doi.org/10.29241/jmk.v2i1.53

Maulana, N. (2020). Menelisik Strategi Pemasaran Rumah Sakit Menggunakan Market Based-Management. Jurnal Manajemen Bisnis, 17(3), 374. https://doi.org/10.38043/jmb.v17i3.2527

Rachmi, P. N. (2020). Gambaran Bauran Promosi Unit Pemasaran Rumah Sakit Islam Surabaya. VISIKES: Jurnal Kesehatan Masyarakat, 19(1), 25-40. http://publikasi.dinus.ac.id/index.php/visikes/article/view/3760

Rahardi, K. P. (2017). Strategi Komunikasi Pemasaran Terpadu Kafe Gulo Jowo di Kota Solo. In Jurnal Manajemen Komunikasi: Vol. 3 (1).

Rahmawati. (2018). Analisis Produk Layanan Rumah Sakit dalam Lingkup Bauran Pemasaran. Administrasi Rumah Sakit, 5(1), 37-41.

Sugiyono. (2017). Metode Penelitian Kuantitatif, Kualitatif, dan R\&D. Bandung : 
Alfabeta, CV.

Tjiptono, Fandy, Ph.D dan Gregorius Chandra.(2016). Service, Quality \& Satisfaction edisi 3 ,Yogyakarta: Andi.

Undang-Undang Republik Indonesia Nomor 44 Tahun 2009 Tentang Rumah Sakit. 2009. diakses di http://dkk.balikpapan.go.id/assets/files/1.UU44-09RS_.pdf pada tanggal 13 Januari 2021

Wahyuni, D. (2019). Strategi Komunikasi Pemasaran Rumah Sakit Mata Pekanbaru Eye Center (PBEC) Dalam Membangun Brand Awareness. In Jom Fisip (Vol. 6, Issue 1).

Wijaya, S., \& Adriansyah, A. A. (2020). Efektivitas Pelaksanaan Marketing Mix 9P Terhadap Kepuasan Pelayanan Klinik Rawat Jalan Rumah Sakit. Jurnal Manajemen Kesehatan Yayasan RS.Dr. Soetomo, 6(1), 28. https://doi.org/10.29241/jmk.v6i1.279

\begin{tabular}{|l|l|}
\hline Submission & $30-04-2021$ \\
\hline Review & $30-05-2021$ \\
\hline Accepted & $01-09-2021$ \\
\hline Publish & $29-10-2021$ \\
\hline DOI & $10.29241 /$ jmk.v7i2.619 \\
\hline Sinta Level & 3 (Tiga) \\
\hline
\end{tabular}

